\title{
ANALISIS UNSAFE ACT DAN UNSAFE CONDITION PADA PROYEK PEMBANGUNAN GEDUNG $X$
}

\author{
Filbert Chance Gondosiswanto ${ }^{1}$ dan $^{\text {Andi }^{2}}$
}

\begin{abstract}
ABSTRAK : Kecelakaan kerja sangatlah rawan terjadi pada sebuah proyek konstruksi dan dapat mengakibatkan kerugian berupa kerusakan pada material maupun peralatan. Kecelakaan kerja yang timbul biasanya disebabkan oleh dua hal yaitu tindakan tidak aman yang dilakukan oleh pekerja (unsafe act) dan kondisi fisik atau lokasi proyek yang tidak aman (unsafe condition). Pada penelitian ini akan dilakukan analisis dan evaluasi tentang tindakan tidak aman (unsafe act) dan kondisi tidak aman (unsafe condition) pada proyek pembangunan gedung $X$.

Faktor perlengkapan pelindung tubuh dan penggunaan peralatan kerja mendapatkan nilai rata-rata terburuk yaitu -1 . Setelah didapatkan hasil tersebut, dilakukan penekanan akan pentingnya pelatihan keselamatan. Penekanan pada pelatihan pekerja menghasilan peningkatan yang cukup baik dari nilai -1 pada proyek hotel maupun soho untuk faktor perlengkapan pelindung tubuh meningkat menjadi 0.69 untuk hotel dan 0.68 untuk soho, untuk faktor penggunaan perlengkapan kerja dari rating -1 untuk hotel dan soho meningkat menjadi 0.56 untuk hotel dan 0.64 untuk soho.
\end{abstract}

Kata kunci: unsafe act, unsafe condition, kecelakaan kerja, proyek konstruksi.

ABSTRACT: Workplace accidents are easily occur on a construction project and may result in losses in the form of damage of materials and equipment. Accidents that arise are usually caused by two things, unsafe actions performed by workers and unsafe physical condition or location of the project. This research will carry out the analysis and evaluation of unsafe acts and conditions of $X$ building project in Surabaya.

Rating is evaluated from several factors that have been determined to cause the accidents. The body protective gear and the use of work equipment factor get the worst average value of -1 . Those results lead to the approach and the special supervision during the training that has been planned. Approach to workers and oversight conducted on the training followed by the workers showed a pretty good improvement based on the increase from the value of -1 on the project of hotel and soho for the body protective equipment factor to 0.69 for hotel and 0.68 for soho. As for the work equipment utilization factor increased from -1 for hotels and soho to 0.56 for hotel and 0.64 for soho.

Keywords : unsafe act, unsafe condition, work accident, construction project.

\footnotetext{
${ }^{1}$ Mahasiswa Program Studi Magister Teknik Sipil Universitas Kristen Petra, m01514002@john.petra.ac.id

2 Dosen Program Studi Magister Teknik Sipil Universitas Kristen Petra, andi@petra.ac.id
} 


\section{PENDAHULUAN}

1.1. Latar Belakang

Kecelakaan kerja sangatlah rawan terjadi pada sebuah proyek konstruksi dan dapat mengakibatkan kerugian berupa kerusakan pada material maupun peralatan. Selain itu dampak dari kecelakaan kerja juga dapat mengakibatkan terjadinya luka bahkan meninggalnya pekerja. Pemerintah Indonesia telah mengeluarkan undang - undang Keselamatan dan Kesehatan Kerja (K3) mengenai program K3 yang digunakan untuk menanggulangi bahaya saat pengerjaan proyek. Program K3 tersebut mengatur suatu upaya untuk mencegah timbulnya kecelakaan dan penyakit akibat kerja dengan cara mengenali hal - hal yang berpotensi menimbulkan kecelakaan dan penyakit tersebut serta menentukan tindakan antisipatif untuk menanggulanginya.

Namun pada pelaksanaannya, program K3 yang sudah dibuat sering kali diabaikan oleh para pekerja dan bahkan oleh pimpinan proyek sehingga pada saat pengerjaan proyek besar kemungkinan terjadi kecelakaan kerja. Kecelakaan kerja yang timbul biasanya disebabkan oleh dua hal yaitu tindakan tidak aman yang dilakukan oleh pekerja (unsafe act) dan kondisi fisik atau lokasi proyek yang tidak aman (unsafe condition). Oleh karena itu, perlu dianalisa lebih lanjut agar dapat mengetahui dan menilai tindakan tidak aman (unsafe act) dan kondisi tidak aman (unsafe condition) dari suatu proyek konstruksi.

Pada penelitian ini akan dilakukan analisa dan evaluasi tentang tindakan tidak aman (unsafe act) dan kondisi tidak aman (unsafe condition) pada proyek pembangunan gedung $\mathrm{X}$.

\subsection{Rumusan Masalah}

Faktor tindakan tidak aman (unsafe act) dan kondisi tidak aman (unsafe condition) apa saja yang terjadi pada proyek pembangunan gedung $X$ sebelum dan setelah penekanan pelatihan keselamatan?

\subsection{Tujuan Penelitian}

Menganalisa faktor tidak aman (unsafe act) dan kondisi tidak aman (unsafe contidition) yang terjadi pada proyek pembangunan gedung $X$ sebelum dan setelah penekanan pelatihan keselamatan.

\subsection{Manfaat Penelitian}

Memberikan pengetahuan dan pengalaman nyata dan secara langsung di lapangan mengenai pentingnya unsafe act dan unsafe condition pada penerapan program K3 di proyek pembangunan gedung $X$.

\section{LANDASAN TEORI}

\subsection{Pendahuluan}

Keselamatan kerja sudah seharusnya menjadi prioritas utama pada setiap industri. Di dalam industri konstruksi, keselamatan kerja membutuhkan perhatian yang lebih besar daripada industri yang lainnya. Hal ini disebabkan karena sering terjadi situasi-situasi dan tindakan bahaya yang membahayakan dalam pekerjaan konstruksi.

\subsection{Keselamatan Kerja}

Keselamatan kerja merupakan keselamatan yang berhubungan dengan mesin, pesawat, alat kerja, bahan dan pengolahannya, landasan tempat kerja dan lingkungannya, serta cara - cara melakukan pekerjaan (Suma'mur, 1989). Undang-Undang No. 1 tahun 1970 menerangkan bahwa keselamatan kerja yang mempunyai ruang lingkup yang berhubungan dengan mesin, landasan tempat kerja dan lingkungan kerja, serta cara mencegah terjadinya kecelakaan dan penyakit akibat kerja, memberikan perlindungan sumber-sumber produksi sehingga dapat meningkatkan efisiensi dan produktifitas. 


\subsection{Kecelakaan Kerja}

kecelakaan kerja merupakan kejadian yang terjadi tanpa disengaja dan dapat mendatangkan kerugian pada proyek secara keseluruhan maupun pada pekerja yang mengalami kecelakaan. Karena itu sangatlah penting untuk meminimalkan kecelakaan kerja hingga seminim mungkin agar tidak terjadi kerugian terutamadalam segi biaya dan waktu.

\subsection{Unsafe Act}

Unsafe act dapat dikatakan sebagai semua tindakan yang dilakukan oleh seseorang yang mengabaikan faktor - faktor keselamatannya, dimana tindakan - tindakannya tersebut dapat membahayakan dirinya sendiri, orang lain, peralatan maupun lingkungan yang ada di sekitarnya.

\subsection{Unsafe Condition}

Unsafe condition dapat dikatakan sebagai semua kondisi yang dapat membahayakan dirinya sendiri, orang lain, peralatan maupun lingkungan yang ada di sekitarnya.

\subsection{Scoring dan Perhitungan Rating Unsafe Act dan Unsafe Condition}

Angka rating menunjukkan kisaran nilai dari 0 sampai 1 maka tingkat keamanannya masih dalam kondisi safe, demikian sebaliknya bila menunjukkan kisaran dari 0 sampai $(-1)$ maka digolongkan dalam kondisi unsafe. Untuk perhitungan rating digunakan rumus sebagai berikut (Salem, 2007) :

Rating $=[\Sigma($ Tindakan safe $)-\Sigma($ Tindakan Unsafe $)] /[\Sigma($ Tindakan Safe dan Tindakan Unsafe)]

Rating $=[\Sigma$ (Kondisi safe $)-\Sigma($ Kondisi Unsafe $)] /[\Sigma$ (Kondisi Safe dan Kondisi Unsafe)]

\section{METODOLOGI PENELITIAN}

\subsection{Umum}

Pada bab ini akan dibahas mengenai metodologi yang akan digunakan untuk menarik kesimpulan sesuai dengan tujuan penelitian penelitian. Diagram alur penelitian dapat dilihat pada Gambar 1.

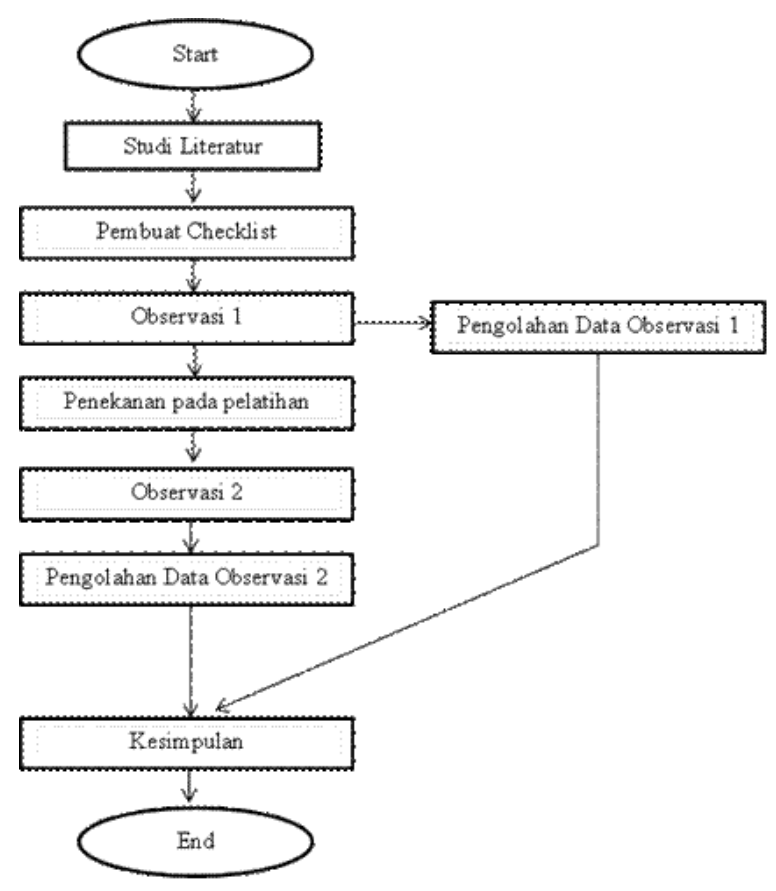

Gambar 1. Flowchart Metode Penelitian 


\subsection{Studi Literatur}

Studi literatur diambil dari referensi buku - buku, internet, dan jurnal - jurnal yang ada di perpustakaan Universitas Kristen Petra. Dari studi literatur ini didapatkan metode yang digunakan untuk merencanakan, menilai, dan mengevaluasi unsafe act dan unsafe condition di proyek.

\subsection{Pembuatan Checklist}

checklist yang dibuat adalah daftar tindakan safe dan tindakan unsafe, serta kondisi lingkungan kerja safe dan unsafe di setiap bidang kerja. Dari checklist tersebut kemudian digunakan untuk mengambil data - data yang akan diamati di lapangan.

\subsection{Observasi 1 dan 2}

Observasi yang dilakukan pada penelitian ini dibagi menjadi dua bagian dengan menggunakan form checklist yang sama. Observasi yang pertama dilakukan pada bulan pertama pengamatan menilai unsafe act dan unsafe condition yang apa adanya ada di proyek. Observasi yang kedua dilakukan pada bulan kedua mengamati unsafe act yang ada di proyek setelah penekanan dilakukan pada pekerja terhadap pelatihan keselamatan. Pengamatan dilakukan setiap hari mulai jam 10 pagi sampai jam 3 sore. Hal - hal yang diamati adalah semua katerogi checklist yang sudah dibuat.

\subsection{Penekanan pada Pelatihan Keselamatan}

Daftar pelatihan yang dibutuhkan pada penelitian ini diambil dari daftar pelatihan milik kontraktor yang terdapat di SHE plan. Tujuan dari pelatihan ini adalah untuk memberi bekal kepada setiap pekerja tentang program K3 agar dapat menghindari risiko kecelakaan kerja yang sewaktu - waktu bisa timbul.

Daftar pelatihan yang sudah ada pada SHE plan sebenarnya sudah sangat baik, tetapi penekanan akan pentingnya pelatihan keselamatan dilakukan dengan ketat guna mendapatkan hasil yang lebih maksimal.

Sesi penekanan pelatihan keselamatan dilakukan pada jeda setelah observasi 1 selesai dan sebelum observasi 2 dimulai. Peneliti mendampingi pimpinan divisi K3 milik kontraktor untuk memberikan arahan yang menjelaskan mengenai pentingnya keselamatan dan sangsi tambahan yang akan diberikan jika tindakan tidak aman tetap sering dilakukan.

\subsection{Pengolahan Data Checklist Observasi 1 dan 2}

Pengolahan data yang dilakukan pada penelitian ini adalah dengan rating, dimana diperoleh rumusan rating adalah sebagai berikut :

Rating unsafe act $=[\Sigma($ Tindakan safe $)-\Sigma($ Tindakan Unsafe $)] /[\Sigma($ Tindakan Safe dan Tindakan Unsafe)]

Rating unsafe condition $=[\Sigma($ Kondisi safe $)-\Sigma($ Kondisi Unsafe $)] /[\Sigma($ Kondisi Safe dan Kondisi Unsafe)]

Pemberian nilai rating ini berdasarkan range dari -1 hingga 1 . Nilai -1 menunjukan indikasi bahwa grup pekerja atau kondisi lapangan yang benar-benar buruk dan sangat berbahaya (unsafe). Pemberian nilai 1 jika grup pekerja atau kondisi menunjukan safe atau aman dan sesuai standar yang diberikan oleh pihak manajemen. Jika hasil rating sama dengan 0 berarti pekerja melakukan tindakan safe dan unsafe hampir sama banyak.

\section{ANALISA DAN PEMBAHASAN}

\subsection{Pendahuluan}

\subsubsection{Gambaran Umum Penelitian}

Dalam bab ini akan dilakukan analisa tentang tindakan tidak aman (unsafe act) dan kondisi tidak aman (unsafe condition) beserta pengaruh penerapan penekanan pelatihan keselamatan pada proyek pembangunan gedung $X$.

Pengumpulan data dan pelaksanaan pengamatan dilakukan mulai tanggal 11 Januari 2016 hingga tanggal 13 Maret 2016. Data form checklist diambil dari daftar tindakan safe dan 
tindakan unsafe, serta kondisi lingkungan kerja safe dan unsafe seperti yang sudah dijelaskan pada Bab 3 subbab 3.3. Sedangkan untuk daftar training diambil dari daftar training milik kontraktor.

\subsubsection{Gambaran Umum Proyek}

Proyek $X$ adalah proyek 3 gedung tinggi yang dibuat untuk perkantoran dan hotel di Kota Surabaya. Gedung tersebut terdiri dari gedung office yang terletak di sebelah utara area proyek, gedung SOHO di sebelah timur area proyek dan gedung hotel yang terletak di sebelah barat area proyek.

\subsection{Daftar Training}

Pada proyek pembangunan gedung X, terdapat departemen SHE (Safety, Health, \& Environment) yang membuat daftar pelatihan (training) untuk membekali para pekerja saat melakukan pekerjaan. Kegiatan training yang dilakukan oleh SHE adalah SHE induction dan SHE talk.

\subsection{Rekapitulasi Hasil Rating Unsafe Act (Sebelum dan Sesudah Penekanan)}

Faktor perlengkapan pelindung tubuh yang mendapat rating -1 sebelum pengawasan meningkat menjadi 0.69 untuk hotel dan 0.68 untuk soho, faktor tindakan tidak aman yang semula bernilai -0.59 untuk hotel dan -0.62 untuk soho meningkat menjadi 0.29 untuk hotel dan 0.31 untuk soho, faktor posisi saat bekerja yang bernilai konstan -0.71 untuk hotel dan soho meningkat menjadi 0.39 untuk hotel dan 0.25 untuk soho, dan faktor penggunaan peralatan saat bekerja yang sebelumnya selalu mendapat rating -1 untuk hotel dan soho, meningkat cukup baik menjadi 0.56 untuk hotel dan 0.64 untuk soho.

\subsection{Rekapitulasi Hasil Rating Unsafe Condition}

Data faktor kondisinya sudah sangat baik karena baik faktor Housekeeping lapangan kerja, Faktor elektrikal dan pencahayaan lingkungan kerja, maupun faktor perlindungan terhadap kecelakaan di lingkungan kerja semua mendapat rating maksimal senilai 1.

\subsection{Pembahasan Hasil Rating Unsafe Act (Sebelum dan Sesudah Penekanan)}

Dari hasil yang didapatkan dapat ditarik kesimpulan bahwa faktor tindakan tidak aman yang paling sering dilakukan pekerja ialah faktor perlengkapan pelindung tubuh baik pada tower hotel maupun $\mathrm{SOHO}$, juga faktor penggunaan peralatan pada hotel dan $\mathrm{SOHO}$.

Dari grafik - grafik di atas juga dapat dilihat bahwa SHE training plan yang dimiliki proyek ini sebenarnya sudah baik, karena ketika dilakukan penekanan saat melakukan pelatihan keselamatan, peningkatan kesadaran para pekerja terhadap peraturan keamanan menunjukan peningkatan yang cukup baik.

\section{KESIMPULAN DAN SARAN}

\subsection{Kesimpulan}

Dari hasil analisa tentang tindakan tidak aman (unsafe act) dan kondisi tidak aman (unsafe condition) pada proyek pembangunan gedung $X$ didapatkan beberapa kesimpulan yaitu :

1. Jenis faktor tindakan tidak aman yang paling sering dilakukan pekerja ialah faktor perlengkapan pelindung tubuh dan faktor penggunaan peralatan yang mendapat rating - 1 selama 28 hari baik untuk hotel dan $\mathrm{SOHO}$.

2. Untuk faktor kondisinya sudah sangat baik karena baik faktor Housekeeping lapangan kerja, Faktor elektrikal dan pencahayaan lingkungan kerja, maupun faktor perlindungan terhadap kecelakaan di lingkungan kerja semua mendapat rating maksimal senilai 1.

3. Penekanan akan pentingnya pelatihan keselamatan yang diikuti para pekerja menghasilkan peningkatan yang cukup baik berdasarkan dengan rating yang didapatkan. Faktor perlengkapan pelindung tubuh yang mendapat rating -1 sebelum 
pengawasan meningkat menjadi 0.69 untuk hotel dan 0.68 untuk soho, faktor tindakan tidak aman yang semula bernilai -0.59 untuk hotel dan -0.62 untuk soho meningkat menjadi 0.29 untuk hotel dan 0.31 untuk soho, faktor posisi saat bekerja yang bernilai konstan -0.71 untuk hotel dan soho meningkat menjadi 0.39 untuk hotel dan 0.25 untuk soho, dan faktor penggunaan peralatan saat bekerja yang sebelumnya selalu mendapat rating -1 untuk hotel dan soho, meningkat cukup baik menjadi 0.56 untuk hotel dan 0.64 untuk soho.

4. Karena itu dapat disimpulkan bahwa para pekerja perlu diberi penekanan atas pentingnya pelatihan keselamatan kerja untuk memperoleh kesadaran dan kewaspadaan akan pentingnya keselamatan di proyek.

\subsection{Saran}

Beberapa saran yang dapat diberikan untuk penelitian selanjutnya ialah :

1. Untuk penelitian selanjutnya, diharapkan para peneliti dapat menambah kelompok kerja penelitian, seperti kelompok kerja pengecoran.

2. Selanjutnya, diharapkan para peneliti dapat memperpanjang durasi penelitian guna mendapatkan hasil yang lebih akurat.

3. Diharapkan para peneliti selanjutnya adalah orang yang benar - benar terlibat di proyek dan dapat mempengaruhi kondisi K3 di proyek.

\section{DAFTAR REFERENSI}

Salem, O, dkk. (2007). A Behaviour-Sased Safety Approach for Construction Projects. Proceedings IGLC-15. 261-270. http://iglc.net/conferences/2007/folder.2007-0629.2095743756

Suma'mur. (1989). Keselamatan Kerja dan Pencegahan Kecelakaan. Cetakan Keempat. CV. Haji Mas Agung., Jakarta 